\title{
Screening and Risk Factors Associated with Vulvovaginal Candidiasis Among Pregnant Women
}

\author{
Yugandhara D Hingankar and Vaishali Taksande \\ Department of Obstetrics and Gynaecological Nursing, SRMM College of Nursing, Datta Meghe Institute \\ of Medical Sciences (Deemed to be University), Sawangi (M) Wardha, Maharashtra, India
}

\section{ABSTRACT}

Background: Vulvovaginal candidiasis is nothing but refers to vulval symptoms caused by the yeast which is most common as candida albicans and it's also consisted of, Vaginal burning and itchy rashes around vulval region, trichomonas vaginalis which leads to fishy smell with greyish discharge. Objective: 1 . To assess vulvovaginal candidiasis among pregnant women. 2. To identify risk of developing vulvovaginal candidiasis among pregnant women. 3. To associate risk factors score of vulvovaginal candidiasis among pregnant women with their demographic variables. The purpose of this study was to assess vulvovaginal candidiasis and to identify risk factors among pregnant women in selected hospital. Material and method: The quantitative research approach and descriptive research design were used. Setting of the study: The study was conducted in Gynae OPD from selected hospital of Wardha District and 43 Pregnant women were selected with non-probability convenient sampling technique. High vaginal swabs were collected from each and processed by Gram Staining, culture on Sabroud's dextrose agar \&t CHROM agar. Result: The findings of this study shows that out of 43 pregnant women 4 were positive for vulvovaginal candidiasis, and 11.93\% of total pregnant women were at the risk and $88.37 \%$ of all total pregnant women were at no risk for vulvovaginal candidiasis. Significant association found between age and trimester in pregnancy. Whereas occupation, monthly income, gravida and education didn't show any significant association with risk factors score. Conclusion: Reproductive age group women and third trimester of pregnant women have more risk of developing vulvovaginal candidiasis. Hence it is necessary to screen for high vaginal swab to reduce the risk of developing vulvovaginal candidiasis among pregnant women.

KEY WORDS: VULVOVAGINAL CANDIDIASIS, REPRODUCTIVE AGE, TRIMESTER, PREGNANT WOMEN, SCREENING, RISK FACTORS.

\section{INTRODUCTION}

Vulvovaginal candidiasis is a type of mucosal infection of a female genital tract of women which is most commonly caused by candida albicans. It is characterized by itching in vagina, burning sensation, soreness near vaginal area, atypical vaginal discharge, dyspareunia, vaginal erythema and oedema. Which are related with vulvovaginal candidiasis results in changes or imbalance in sexual hormone, and its result to usage of contraceptive pills, pregnancy or therapy for hormone replacement as well as using antibiotic in the case of diabetes mellitus. Many incidents of vulvovaginal candidiasis re-join to remedy

Biosc Biotech Res Comm P-ISSN: 0974-6455 E-ISSN: 2321-4007
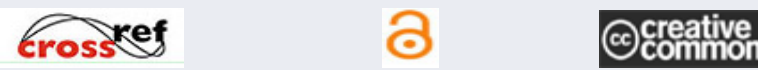

Identifiers and Pagination

Article Information

Year: 2021 Vol: 14 No (9) Special Issue

Received: $17^{\text {th }}$ May 2021

Pages: $49-54$

Accepted after revision: $05^{\text {th }}$ July 2021

This is an open access article under Creative

Commons License Attribn 4.0 Intl (CC-BY).

DOI: $h t t p: / / d x . d o i . o r g / 10.21786 / b b r c / 14.9 .11$ which is recently available antifungal during acute vulvovaginal candidiasis is mostly curable with recent chemotherapeutic and stay in their place for subset of the population among females those who are diagnosed with vulvovaginal candidiasis. Primary infection is arising and it is not connected with any make susceptible factors to find out with acute vulvovaginal candidiasis.

Hormonal replacement therapy and diabetes mellitus are secondary predisposing factors been noted. Females those who are diagnosed with recurrent vulvovaginal candidiasis specifically responds to antifungal treatment because of little aversion to the disease. Vulvovaginal is one of the common infections that nurses deal with daily. Yeast infection are not always be prevented so however, that are associated with specific risk. Factors that nurses can counsel women to alert or avoid. There are three main cause of infection those are bacterial vaginosis, vaginal yeast infection, and trichomoniasis. Despite of these there are many other causes which includes allergies related to any substance from soap or spermicides, and it leads to 
decrease in oestrogen level at the time of breastfeeding and menopause and these causes are changes as the age varies.

These complications may lead to regular discomfort such as daily discomfort, infection of skin and many more, because of rashes scraping, and other causative conditions includes candida infections and Neisseria gonorrhoea. The diagnosis of these disease is done according to patients' condition, microscopic examination and culture is done to examine the growth of the yeast by discharge. Many advices which are given the following are keeping the genital area clean and dry, its more necessary to keep it clean and rising with only plain water only. Yes, it is necessary to clean vagina after sexual contact and menstruations but using douching may be harmful in many conditions. Using of condoms are suggested to avoid any kind of sexually transmitted diseases. Antibiotic therapies are recommended to prevent the yeast infections.

\section{METHODS}

The researcher has adopted descriptive research design to assess the risk factors of vulvovaginal candidiasis among pregnant women, it provides the best framework for the study. The present study aims are to assess vulvovaginal candidiasis and associated risk factors among pregnant women in selected hospital. The researcher has adopted quantitative research approach. The research from the tool after updating theoretical risk factors associated vulvovaginal candidiasis, where it will help to rule out the incidence of vulvovaginal candidiasis among reproductive female. At the beginning, patients form outpatient department that are pregnant women had been be tested those who have come for regular antenatal check-ups. Females with symptoms and without symptoms are selected for this study. Structured questioner on demographic variables and observe by using risk factors assessment scale for vulvovaginal candidiasis.

High vaginal swab was taken from every patient, each sample required 15 mins of time to finish this procedure, and the sample were sent to microbiology department for further investigations. The Sample collections process started from the researchers visited to Rural hospital AVBRH Sawangi (M) Wardha city and had taken necessary permissions from authorities. Before the procedure of data collection permission were taken from involved committees, Prior permission was taken from HOD of Dept of OBGY to conduct this study. The researches selected the ANC mothers from OPD those visited for their regular check-up with the following inclusion and exclusion criteria, the researcher explain the patients regarding vaginal candidiasis and its complication to foetus in future, and also explain them awareness regarding this condition and preventive measures.

Written consent is taken from every participant before starting the procedure. High vaginal swab was taken from every participant's swab were preserved and send to microbiology department for further process, later questions were asking regarding demographic variables and risk factors assessment scale were given for detection risk of developing vulvovaginal candidiasis among them. The pregnant women will be surveyed to assess the risk factor of vaginal candidiasis by using risk assessment scale. Risk status was classified with "no risk" means NO with the score "zero", "with risk" means YES with the score of "one". And it is distributed accordingly, No risk (0) With Risk (1-20) and it was based on total number of responses given by pregnant women. The Datta Meghe Institute of Medical Sciences' Ethics Committee (DU); the report was accepted by the Institutional Ethics Committee.

\begin{tabular}{|c|c|c|}
\hline Demographic Variables & Frequency (f) & Percentage (\%) \\
\hline \multicolumn{3}{|l|}{ Age(yrs.) } \\
\hline $18-22$ yrs. & 8 & 18.6 \\
\hline $23-28$ yrs. & 20 & 46.5 \\
\hline $29-34$ yrs. & 15 & 34.9 \\
\hline $35-40$ yrs. & 0 & 0 \\
\hline \multicolumn{3}{|l|}{ Education } \\
\hline Illiterate & 0 & 0 \\
\hline Primary & 3 & 7.0 \\
\hline Secondary & 11 & 25.6 \\
\hline Higher Secondary & 19 & 44.2 \\
\hline Graduate & 10 & 23.3 \\
\hline \multicolumn{3}{|l|}{ Occupation } \\
\hline Govt. Sector & 2 & 4.7 \\
\hline Private Sector & 5 & 11.6 \\
\hline Homemaker & 32 & 74.4 \\
\hline Unemployed & 4 & 9.3 \\
\hline \multicolumn{3}{|c|}{ Monthly family income (Rs) } \\
\hline$<5000 \mathrm{Rs}$ & 3 & 7.0 \\
\hline 5001-10000 Rs & 31 & 72.1 \\
\hline $10001-20000$ Rs & 5 & 11.6 \\
\hline$>20000 \mathrm{Rs}$ & 4 & 9.3 \\
\hline \multicolumn{3}{|l|}{ Gravida } \\
\hline Primigravida & 19 & 44.2 \\
\hline Multigravida & 24 & 55.8 \\
\hline \multicolumn{3}{|l|}{ Trimester } \\
\hline First & 1 & 2.3 \\
\hline Second & 14 & 32.6 \\
\hline Third & 28 & 65.1 \\
\hline
\end{tabular}

Statistical Analysis: All findings were summarized by concentrations and percentages, categorically. The program used in the study was SPSS 24.0 and the edition of Graph Pad Prism 7.0, and $p<0.05$ is regarded as a degree of significance. Descriptive statistics are used to describe the basic features of the data in a study. They provide simple summaries about the sample and the measures. Together with simple graphics analysis, they 
form the basis of virtually every quantitative analysis of data.

\section{RESULTS}

The analysis and interpretation of the data collected from 43 samples who were pregnant women. The analysis was done with the help of inferential and descriptive statistics. The Section deals with demographic variables such as age, education, occupation, monthly income, gravida and trimester.

Table 2. Assessment of vulvovaginal candidiasis among pregnant women $n=43$

\begin{tabular}{|l|c|c|}
\hline $\begin{array}{l}\text { Vulvovaginal candidiasis } \\
\text { (Candida albicans) }\end{array}$ & Frequency & Percentage (\%) \\
\hline Present & 4 & $9.30 \%$ \\
\hline Absent & 39 & $90.70 \%$ \\
\hline Total & 43 & 100 \\
\hline
\end{tabular}

Table 3. Frequency and percentage distribution of findings for vulvovaginal candidiasis $n=43$

\begin{tabular}{|c|c|c|c|c|c|}
\hline \multirow{2}{*}{$\begin{array}{c}\text { Sr. } \\
\text { No }\end{array}$} & \multirow{2}{*}{ Organism Found } & \multicolumn{2}{|c|}{ Positive } & \multicolumn{2}{c|}{ Negative } \\
\cline { 3 - 6 } & & F & $\%$ & F & $\%$ \\
\hline 1 & Candida Albicans (vulvovaginal candidiasis) & 4 & 9.30 & 39 & 90.70 \\
\hline 2 & Escherichia Coli & 3 & 6.98 & 40 & 93.02 \\
\hline 3 & Klebsiella Pneumoniae & 2 & 4.65 & 41 & 95.35 \\
\hline 4 & Normal flora grown & 6 & 13.95 & 37 & 86.05 \\
\hline 5 & Not even nomal flora grown & 28 & 65.12 & 15 & 34.88 \\
\hline
\end{tabular}

Figure 1: Frequency and percentage distribution of findings for vulvovaginal candidiasis

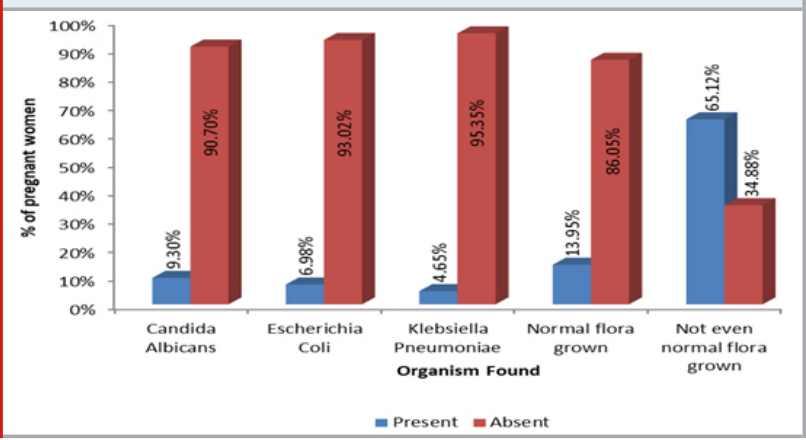

This table states the distribution of pregnant women according to their demographic variables in this table it is distributed as age in years pregnant women were found 18-22yrs the total frequency was 8(18.6\%), 23$28 y r s$ frequency was $20(46.5 \%)$, the age group of 2934yrs was $15(34.9 \%)$, whereas the last age group that is of 35-40yrs no women was present. This shows the percentage wise distribution of educational status which includes, illiterate women were 0 , primary education was $3(7.0 \%)$ women, secondary education was $11(25.6 \%)$ women were found, whereas higher secondary education was 19(44.2\%) women and Graduate were 10(23.3\%) women were observed. The distribution was according to occupation status it includes government sectors 2(4.7\%),
Private sector was 5(11.6\%), whereas homemaker was $32(74.4 \%)$ and unemployed was 4(9.3\%).

The table shows distribution of monthly income of family were women with < 5000Rs was $3(7.0 \%)$, women with family income between 5001-10000Rs was 31(72.1\%), and Women who had family income from 10001-20000Rs was $5(11.6 \%)$ and women with $>20000$ Rs were $4(9.3 \%)$ are following distribution of income. The distribution of gravida of women are primigravida and multigravida. The distribution shows $19(44.2 \%)$ of women are primigravida and $24(55.8 \%)$ of women are multigravida. The table shows distribution of trimester of pregnant women it indicates that $1(2.3 \%)$ is of first trimester, $14(32.6 \%)$ of women are from second trimester and 28(65.1\%) of pregnant women were from third trimester.

Findings of vulvovaginal candidiasis among pregnant women in selected hospitals of Wardha district. The total women were selected for the study was 43, and among that it shows that $4(9.30 \%)$ of pregnant women had vulvovaginal candidiasis, however 39(90.70\%) of pregnant women didn't have vulvovaginal candidiasis. According to above table it indicates the distribution of vulvovaginal candidiasis and other organisms, In the present study among 43 pregnant women, 4(9.30\%) of pregnant women were positive for vulvovaginal candidiasis it indicates the presence of candida albicans which is a type of yeast. Escherichia coli 3(6.98\%) was present among pregnant women, 2(4.65\%) of pregnant women were positive for Klebsiella Pneumoniae, in $6(13.95 \%)$ pregnant women normal flora grown was present, and 28(65.12\%) where not even normal flora growth has been observed among pregnant women. Assessment of risk factor associated with vulvovaginal candidiasis among pregnant women from selected hospital. Percentage and frequency wise distribution of risk factors of vulvovaginal candidiasis

According to the table there are distribution of the risk factors which shows the pregnant women with risk and no risk. Severe vaginal discharge $29(67.44 \%)$ are with risk and $14(32.56 \%)$ are with no risk were present in pregnant women, vulval itching $18(41.86 \%)$ pregnant women are with risk and 25(58.14\%) women are with no risk. $2(4.65 \%)$ of women were with the previous history of vulvovaginal candidiasis they are with risk and $41(95.35 \%)$ of women are with no risk, $17(39.53 \%)$ of pregnant women were using oral contraceptive users are were at risk and 26(60.47\%) of pregnant women are with no risk. The recent antibiotics user was not present in the study $43(100.00 \%)$ of women are with no risk. $4(9.30 \%)$ of pregnant are of diabetes are with risk and 39(90.70\%) of pregnant women did have the risk, 43(100.00\%) of pregnant women are with no risk for steroids users, not a single woman is found with risk in it. 24(53.48\%) of women were with risk in multipara and 19(44.18\%) of women were with no risk. Taking anti-allergic drugs for allergy in pregnant women were $1(2.33 \%)$ of them were with risk and $42(97.67 \%)$ of pregnant women are with no risk. 11 (25.58\%) of pregnant women were suffering from anaemia and are with risk and 32 (74.42\%) of 
them are with no risk. 4 (9.30\%) of pregnant women were Suffering from Hypothyroidism with the risk and $39(90.70 \%)$ of pregnant women are with no risk found.

Not a single woman is found with risk for worm infestation problem which means $43(100.00 \%)$ of all pregnant women are with no risk for worm infestation problem. 43(100.00\%) of pregnant women are with no risk for multiple sexual partners, 1 (2.33\%) of pregnant women are with risk for wearing tight undergarments and $42(97.67 \%)$ of them are at no risk. $1(2.33 \%)$ of pregnant women think it is not necessary to change wet undergarments are with risk and 42(97.67\%) of them are with no risk. $2(4.65 \%)$ of pregnant women goes to swimming pool are at risk and remaining 41(95.35\%) are with no risk. 2(4.65\%) of pregnant women are using scented laundry soap are with risk and 41(95.35\%) of women are with no risk. 25(58.14\%) of pregnant women wearing synthetic undergarments are with the risk and remaining $18(41.86 \%)$ of women are with no risk. 4 (9.30\%) of pregnant women are sensitive to any perfume or talcum powder and 39(90.70\%) of women are with no risk for using and of the perfume or talcum powder. 29 (67.44\%) of pregnant women have a habit of washing from back to front after using toilets are with the risk and $14(32.56 \%)$ of remaining pregnant women are with no risk in the present study, whereas $11.93 \%$ of pregnant women are with risk and 88.93\% of pregnant women are at no risk.

\begin{tabular}{|c|c|c|c|c|c|}
\hline \multirow[t]{2}{*}{ Sr. No } & \multirow[t]{2}{*}{ Risk for vaginal candidiasis } & \multicolumn{2}{|c|}{$\begin{array}{l}\text { With risk } \\
\text { Yes }\end{array}$} & \multicolumn{2}{|c|}{$\begin{array}{c}\text { No risk } \\
\text { No }\end{array}$} \\
\hline & & $\mathrm{F}$ & $\%$ & $\mathrm{~F}$ & $\%$ \\
\hline 1 & Severe vaginal discharge & 29 & 67.44 & 14 & 32.56 \\
\hline 2 & Valvula itching & 18 & 41.86 & 25 & 58.14 \\
\hline 3 & Previous history of vaginal candidiasis & 2 & 4.65 & 41 & 95.35 \\
\hline 4 & Oral contraceptive pills user & 17 & 39.53 & 26 & 60.47 \\
\hline 5 & Recent antibiotics user & 0 & 0.00 & 43 & 100.00 \\
\hline 6 & Diabetic & 4 & 9.30 & 39 & 90.70 \\
\hline 7 & On steroids & 0 & 0.00 & 43 & 100.00 \\
\hline 8 & Multipara & 24 & 53.48 & 19 & 44.18 \\
\hline 9 & Taking anti-allergic drugs for allergy & 1 & 2.33 & 42 & 97.67 \\
\hline 10 & Suffering from Anemia & 11 & 25.58 & 32 & 74.42 \\
\hline 11 & Suffering from Hypothyroidism & 4 & 9.30 & 39 & 90.70 \\
\hline 12 & Worm infestation problem & 0 & 0.00 & 43 & 100.00 \\
\hline 13 & Multiple sexual partner & 0 & 0.00 & 43 & 100.00 \\
\hline 14 & Wearing tight undergarment's & 1 & 2.33 & 42 & 97.67 \\
\hline 15 & $\begin{array}{l}\text { Think it is not necessary to } \\
\text { change wet undergarment's }\end{array}$ & 1 & 2.33 & 42 & 97.67 \\
\hline 16 & Going to Swimming pool & 2 & 4.65 & 41 & 95.35 \\
\hline 17 & Wearing synthetic undergarments. & 25 & 58.14 & 18 & 41.86 \\
\hline 18 & Using scented laundry soap & 2 & 4.65 & 41 & 95.35 \\
\hline 19 & Sensitive to any perfume or talcum powder & 4 & 9.30 & 39 & 90.70 \\
\hline 20 & Washing from back to front after using toilets. & 29 & $\begin{array}{c}67.44 \\
11.93 \%\end{array}$ & 14 & $\begin{array}{c}32.56 \\
88.37 \%\end{array}$ \\
\hline
\end{tabular}

This table shows the association of risk factor score with age in years of pregnant women. A ' $F$ ' values were 3.23( $\mathrm{df}=2,40)$ it is lesser than evaluated ' $\mathrm{F}$ ' i.e., 9.27at 5\% level of significance. Also, the calculated 'p'=0.0001which was less than the acceptable level of significance i.e., 'p'=0.05. Hence it is interpreted that age in years of pregnant women is statistically associated with their risk factor score. This table shows the association risk factor score with trimester of pregnancy of pregnant women. The tabulated ' $F$ ' values were 3.23 $(\mathrm{df}=2,40)$ which is much less than the calculated 'F' i.e., 17.54 at 5\% level of significance. Also, the calculated 'p'=0.0001 which was much less than the acceptable level of significance i.e., 'p'=0.05. Hence it is interpreted that trimester of pregnancy of pregnant women is statistically associated with their risk factor score.

\section{DISCUSSION}

The study findings were discussed with the references to the objectives stated in chapter 1 and with the findings of other studies in this section. The research study was an undertaken that is "Screening and risk factors associated with vulvovaginal candidiasis among pregnant women." In the present study among, 43(100\%) out of $4(9.31 \%)$ of pregnant women were positive for vulvovaginal candidiasis and all participants include pregnant women from Gynae OPD from selected hospitals 
of wardha district. In the present study researcher found an association in the demographic variable and risk factors score in age and trimester. Women with the age group 18-34years (Reproductive age) have high risk of vulvovaginal candidiasis and also found that women with third trimester of pregnancy have more risk of developing vulvovaginal candidiasis.

Table 5. Assessment of risk factor score among pregnant women. $n=43$

\begin{tabular}{c|c|c|c|} 
Level of screening and & \multirow{2}{*}{ Score Range } & \multicolumn{2}{c|}{ Level of screening and risk factor score } \\
\cline { 2 - 4 } risk factor score & 0 & Frequency (f) & Percentage \\
\hline No risk & 0 & 38 & $88.37 \%$ \\
\hline With Risk & $1-20$ & \multicolumn{2}{|c|}{0} \\
\hline \multicolumn{2}{|c|}{ Minimum score } & \multicolumn{2}{|c|}{7} \\
\hline \multicolumn{2}{|c|}{ Maximum score } & \multicolumn{2}{c|}{$4.04 \pm 1.92$} \\
\hline \multicolumn{2}{|c|}{ Mean score } & \multicolumn{2}{c|}{$20.32 \pm 9.63$} \\
\hline \multicolumn{2}{|c|}{ Mean \% Score }
\end{tabular}

Figure 2: Frequency and percentage distribution of risk factor of vaginal candidiasis

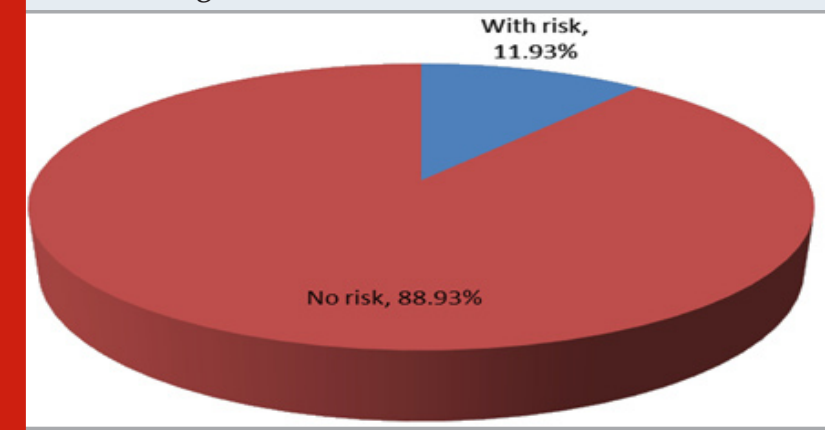

Table 6. Association of risk factor score in relation to age. $\mathrm{n}=43$

\begin{tabular}{|c|c|c|c|c|}
\hline Age (yrs.) & $\begin{array}{c}\text { Frequency } \\
\text { (f) }\end{array}$ & $\begin{array}{c}\text { Mean } \\
\text { score } \pm \text { SD }\end{array}$ & $\begin{array}{c}\text { F- } \\
\text { value }\end{array}$ & $\begin{array}{c}\text { p- } \\
\text { value }\end{array}$ \\
\hline 18-22 yrs. & 8 & $2.12 \pm 1.80$ & 9.27 & $\begin{array}{c}0.0001 \\
\mathrm{Sp}<0.05\end{array}$ \\
\hline $23-28$ yrs. & 20 & $3.45 \pm 1.76$ & & \\
\hline $29-34$ yrs. & 15 & $4.86 \pm 0.74$ & & \\
\hline $35-40$ yrs. & 0 & $0 \pm 0$ & & \\
\hline
\end{tabular}

Table 7. Association of risk factor score in relation to their trimester of pregnancy. $n=43$

\begin{tabular}{|l|c|c|c|c|}
\hline $\begin{array}{l}\text { Trimester } \\
\text { of } \\
\text { pregnancy }\end{array}$ & $\begin{array}{c}\text { Frequency } \\
\text { (f) }\end{array}$ & $\begin{array}{c}\text { Mean } \\
\text { score } \pm \text { SD }\end{array}$ & $\begin{array}{c}\text { F- } \\
\text { value }\end{array}$ & $\begin{array}{c}\text { p- } \\
\text { value }\end{array}$ \\
\hline First & 1 & $0 \pm 0$ & & \\
\hline Second & 14 & $2.28 \pm 1.85$ & 17.54 & $\begin{array}{c}0.0001 \\
\text { Sp }<0.05\end{array}$ \\
\hline Third & 28 & $4.53 \pm 0.96$ & & \\
\hline
\end{tabular}

Similar study was conducted in Mangalore, Karnataka India were 118 pregnant women were analyses and its shows that 50\% of pregnant women were positive for candidiasis and giving the prevalence of $42.37 \%$ which shows that majority of vulvovaginal candidiasis if found in reproductive age that is from 26-30yrs of age, and they conclude that incorporation of a screening protocol in routine antenatal check-up for early diagnosis of candidiasis and its treatment by cost effective drugs should be recommended.9 And another study was conducted in port Hardcourt, River states which aimed was to determine the prevalence of candida albicans among the women, the study shows that 36\% of women had positive for candida albicans and 64\% of women were negative. It concludes that prevalence is higher in pregnant women with a significant relationship with age.

The similar study was conducted in Ghana which aim was to assess the prevalence of vulvovaginal candidiasis among pregnant women. Were the highest frequency of vulvovaginal candidiasis was recorded in pregnant women in their third trimester (57.4\%).11 Further they had concluded with the reason that is the reason is just because pregnancy mostly in the third trimester, levels of oestrogen is specifically high and its result in higher glycogen deposits in the vagina, and this provides a good source of carbon, which supports the proliferation of Candida species. Moreover, oestrogen increases the affinity of Candida to the yeast cytosol receptor in vaginal epithelial cells.

In the present study it was found that among all total majority of $11.93 \%$ of total pregnant women were at the risk and $88.37 \%$ of all total pregnant women were at no risk for vulvovaginal candidiasis. The risk factors were detected among them were that 29(67.44\%) of the pregnant women have habit of washing from back to front after using toilet, 24(53.48\%) of that were multipara and $25(58.14 \%)$ of pregnant women among them were using synthetic undergarments and 11(25.58\%) of pregnant women were suffering from anaemia. The similar study was conducted in Karnataka, India which aimed was to assess the risk of vaginal candidiasis among pregnant women, the study shows that majority that is (53\%) of the pregnant women belongs to no risk category and (47\%) of pregnant women belongs the risk of developing vulvovaginal candidiasis. The risk factors were detected among these pregnant women were 52.8\% of them had the habit of washing from front to back 
after using toilet. 39.4\% were multipara and 39.4\% of the pregnant women had the habit of wearing synthetic undergarments, 35.2\% were using scented laundry soap to clean the perineum each time. $33.8 \%$ of them were suffering from anaemia.

\section{CONCLUSION}

After the detailed analysis, the present study concludes that reproductive age group women and third trimester of pregnant women have more risk of developing vulvovaginal candidiasis. It also found that age and trimester in pregnancy were significantly associated with the risk factor score. It also shows among all total $11.93 \%$ of pregnant women were with the risk of developing vulvovaginal candidiasis and $88.37 \%$ of them were at no risk. In conclusion our current study concludes that reproductive age group women have more risk of developing vulvovaginal candidiasis, because of High oestrogen levels cause an increased glycogen load in epithelium, which is a nutritional source for growth of candida \&t germination. Oestrogen promotes fungal adhesion \& germination, fungi are more capable to penetrate vaginal wall, Vulvovaginal candidiasis the most common gynaecologic diagnosis in the primary care setting. Lactobacillus acidophilus (normal vaginal flora) produces hydrogen peroxide, when balance bacteria and yeast imbalanced it results to rise in hormone levels and moist environment is also a favourable condition of yeast to grow. Which may harm to mother and child too. Hence it is necessary to screen for high vaginal swab to reduce the risk of developing vulvovaginal candidiasis among pregnant women.

\section{REFERENCES}

Alli JA, Okonko IO, Odu NN, Kolade AF, Nwanze JC. (2011) Detection and prevalence of Candida isolates among patients in Ibadan, Southwestern Nigeria. J Microbial Biotech Res.;1(3):176-84.

Christian LM.( 2012) Physiological reactivity to psychological stress in human pregnancy: Current knowledge and future directions. Progress in Neurobiology. Nov 1;99(2):106-16.

Fidel PL.( 2007) History and Update on Host Défense Against Vaginal Candidiasis. American Journal of Reproductive Immunology.;57(1):2-12.

Foxman B.( 1990) The epidemiology of vulvovaginal candidiasis: risk factors. Am J Public Health. Mar 1;80(3):329-31.

Gipson P, King C. (2012) Health Behaviour Theories and Research: Implications for Suicidal Individuals' Treatment Linkage and Adherence. Cognitive and Behavioural Practice. May 1;19(2):209-17.

Ilkit M, Guzel AB. (2011) The epidemiology, pathogenesis, and diagnosis of vulvovaginal candidosis: A mycological perspective. Critical Reviews in Microbiology. Aug 1;37(3):250-61.

Kamath P, Pais M, Nayak MG. Risk of vaginal candidiasis among pregnant women. 2013;7.

Kamath P, Pais M, Nayak MG. Risk of vaginal candidiasis among pregnant women. 2013;7.

Rajeswari S, Sanjeeva Reddy N. (2019) Efficacy of Progressive Muscle Relaxation on Pregnancy Outcome among Anxious Indian Primi Mothers. Iran J Nurs Midwifery Res. Dec 27;25(1):23-30.

Redondo-Lopez V, Cook RL, Sobel JD. (1990) Emerging role of lactobacilli in the control and maintenance of the vaginal bacterial microflora. Rev Infect Dis. Oct;12(5):856-72.

Vaginal infections in pregnant women in Jamaica: prevalence and risk factors, 2000.

Waikhom SD, Afeke I, Kwawu GS, Mbroh HK, Osei GY, Louis B, et al.( 2020) Prevalence of vulvovaginal candidiasis among pregnant women in the Ho municipality, Ghana: species identification and antifungal susceptibility of Candida isolates. BMC Pregnancy Childbirth. May 6;20(1):266. 